\title{
Liver metastasis from papillary thyroid carcinoma treated by laparoscopic hepatectomy 43 years after resection of the primary tumor: a case report
}

\author{
Mariko Tsukagoshi ${ }^{1,2^{*}}$ D, Norifumi Harimoto ${ }^{2}$, Kenichiro Araki ${ }^{2}$, Norio Kubo ${ }^{2}$, Akira Watanabe ${ }^{2}$, Takamichi Igarashi ${ }^{2}$,
} Norihiro Ishii², Toshiki Yajima', Takaaki Sano ${ }^{3}$ and Ken Shirabe ${ }^{2}$

\begin{abstract}
Background: Papillary thyroid carcinoma (PTC) generally has a good prognosis, while liver metastasis from PTC is rare and difficult to diagnose.

Case presentation: A 67-year-old woman was diagnosed with PTC and underwent a left hemithyroidectomy 43 years ago. Two years ago, thoracoscopic right middle lobectomy was performed for a lung tumor, and pathology reports confirmed a metastatic lung tumor of PTC. The patient was followed up regularly with computed tomography, and a liver tumor measuring $16 \mathrm{~mm}$ was found in the lateral segment of the liver. Fluorodeoxyglucose positron emission tomography (FDG-PET) was negative for liver tumor. However, FDG uptake was observed at the nodule outside the right lobe of the thyroid gland, suggesting metastasis to the right supraclavicular lymph node. Laparoscopic partial S2 hepatectomy was performed without complications. The final diagnosis was metastatic liver tumor from PTC, and the surgical margins were free of tumor. Postoperatively, the patient underwent complementary thyroidectomy and right supraclavicular lymph node dissection, followed by I-131 ablation. The final diagnosis was PTC of $7 \mathrm{~mm}$ and $4 \mathrm{~mm}$ and lymph node metastasis of $9 \mathrm{~mm}$. The patient is currently doing well and has had no recurrence 1 year after surgery.
\end{abstract}

Conclusions: This case demonstrates that liver metastases from PTC may be found after long-term follow-up, and liver resection might be the most appropriate treatment.

Keywords: Thyroid cancer, Papillary thyroid carcinoma, Liver metastasis, Liver surgery

\section{Background}

Differentiated thyroid carcinoma (DTC), including follicular and papillary carcinomas, is slow-growing tumors with good prognosis and long-term survival [1-3]. Papillary thyroid carcinoma (PTC) is the most frequent type

\footnotetext{
*Correspondence: marikot@gunma-u.ac.jp

'Department of Innovative Cancer Immunotherapy, Gunma University Graduate School of Medicine, 3-39-22 Showa-machi, Maebashi, Gunma 371-8511, Japan

${ }^{2}$ Division of Hepatobiliary and Pancreatic Surgery, Integrative Center of General Surgery, Gunma University Hospital, 3-39-15 Showa-machi, Maebashi, Gunma 371-8511, Japan

Full list of author information is available at the end of the article
}

of DTC. While PTC commonly metastasizes to regional lymph nodes, the incidence of distant metastases is rare, and the major sites of distant metastases are the lung and bone $[4,5]$. Other sites of distant metastases, such as the liver and brain, are very rare, with a reported frequency of $0.5 \%$ or less [5-8]. These metastases are mostly identified during the course of treatment and follow-up, and recurrences can occur more than 30 years after initial treatment [1]. The presence of distant metastases has almost always been recognized in advanced disease and is often associated with poor outcomes [8]. Thus, early detection of distant metastases influences

\section{Springer Open}

(c) The Author(s). 2020 Open Access This article is licensed under a Creative Commons Attribution 4.0 International License, which permits use, sharing, adaptation, distribution and reproduction in any medium or format, as long as you give appropriate credit to the original author(s) and the source, provide a link to the Creative Commons licence, and indicate if changes were made. The images or other third party material in this article are included in the article's Creative Commons licence, unless indicated otherwise in a credit line to the material. If material is not included in the article's Creative Commons licence and your intended use is not permitted by statutory regulation or exceeds the permitted use, you will need to obtain permission directly from the copyright holder. To view a copy of this licence, visit http://creativecommons.org/licenses/by/4.0/. 
prognosis of the patients. Herein, we report our experience with a rare case of liver metastasis from PTC 43 years after resection of the primary tumor and review the current literature on the topic.

\section{Case presentation}

A 67-year-old woman was referred to our department for investigation of liver tumor. The patient underwent left hemithyroidectomy for PTC 43 years prior. Two years ago, thoracoscopic right middle lobectomy was performed for lung tumor, and the diagnosis was lung metastasis of PTC. Liver tumor was found on subsequent follow-up computed tomography (CT) examinations; therefore, we considered that there was a possibility of liver metastasis of PTC.

Blood biochemical examinations indicated normal liver function tests, while there was no elevation of serum carbohydrate antigen 19-9, carcinoembryonic antigen, or $\alpha$-fetoprotein levels. Abdominal contrast-enhanced ultrasonography showed a $16-\mathrm{mm}$ echo-free image in the lateral segment of the liver and a ring perilesional enhancement from the early phase, which resulted in a defect in the Kupffer phase (Fig. 1a). An enhanced abdominal CT scan revealed a $16-\mathrm{mm}$ marginal enhanced tumor in the lateral segment of the liver (Fig. 1b). The patient underwent fluorodeoxyglucose positron emission tomography (FDG-PET) which was negative for liver tumor (Fig. 1c). Approximately, half of the right thyroid gland showed no definite mass by CT. However, FDG uptake (maximal standardized uptake value $=3.43$ ) was observed at the nodule outside the right lobe of the thyroid gland (Fig. 1c), suggesting metastasis to the right supraclavicular lymph node. The preoperative diagnosis was liver metastasis of PTC, and right supraclavicular lymph node metastasis was also suspected.

We performed laparoscopic partial liver resection for segment 2. The operative procedures in this case and the surgical outcomes are as follows. The patient was placed in the supine position, and six ports were used including a port for Pringle taping. We placed the (a)

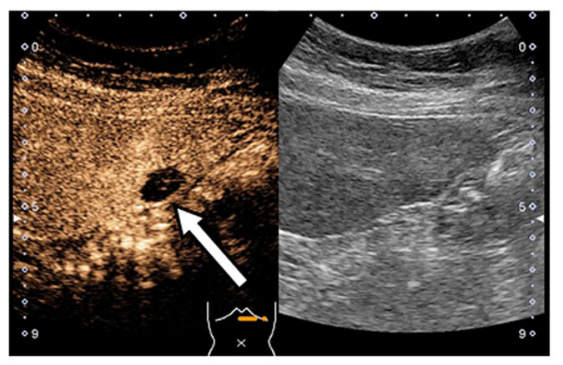

(c)
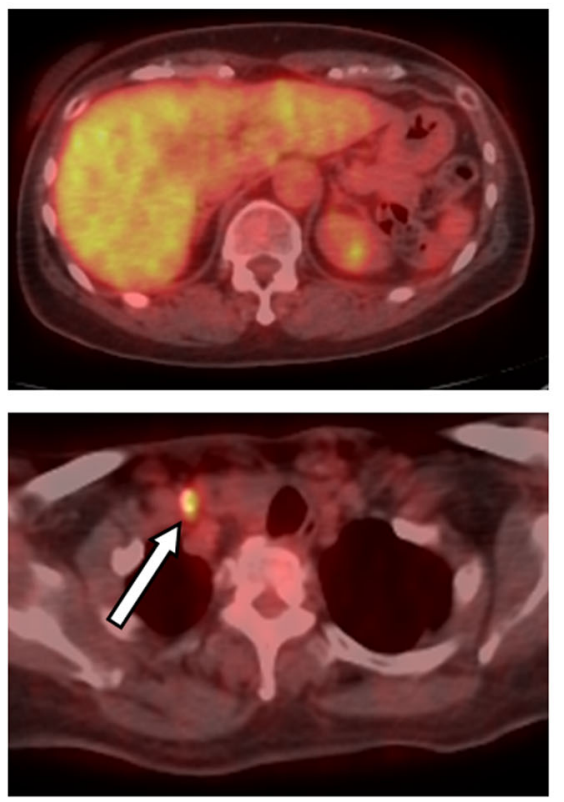

(b)

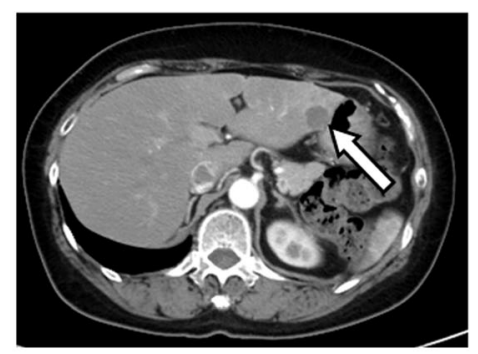

Early phase

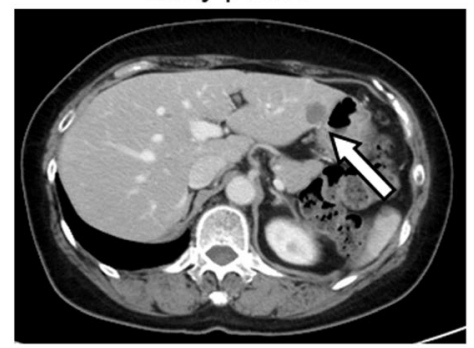

Portal phase

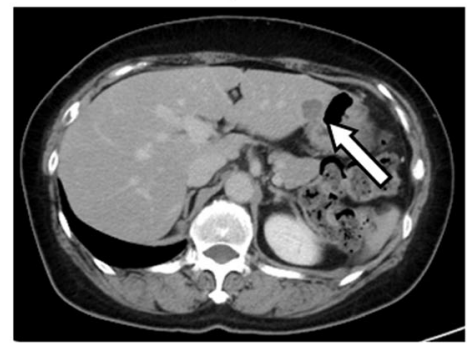

Late phase

Fig. 1 a Abdominal contrast-enhanced ultrasonography shows a 16-mm echo-free mass in the lateral segment of the liver, which resulted in a defect in the Kupffer phase (arrow). b Enhanced abdominal computed tomography scan shows a 16-mm marginally enhanced tumor in the lateral segment of the liver (arrow). c Fluorodeoxyglucose positron emission tomography (FDG-PET) is negative for liver tumors. FDG uptake (maximal standardized uptake value $=3.43$ ) is observed at the nodule outside the right lobe of the thyroid gland (arrow) 
camera port at the umbilical site, and the operating surgeon mainly used two ports placed at the right upper abdomen. Pneumoperitoneum pressure was maintained at $10 \mathrm{mmHg}$. Ultrasonically activated scalpels and Cavitron Ultrasonic Surgical Aspirator (CUSA; AMCO Inc., Tokyo, Japan) were used for transection of the liver parenchyma. Hemostasis was performed using the tip of the CUSA connected to a VIO 300 D generator (ERBE Elektromedizin $\mathrm{GmbH}$, Tubingen, Germany) and bipolar forceps held in the operator's left hand, both at soft-coagulation mode [9]. An intermittent pedicle clamp (15 min occlusion and 5 min reperfusion, Pringle method) was used during parenchymal transection. Under anesthesia, hemodynamic management aimed to maintain low central caval pressure was used to minimize blood loss with reduced volume perfusion $[10,11]$. Airway pressure was maintained between 14 and $16 \mathrm{cmH}_{2} \mathrm{O}$ to reduce central venous pressure and volume perfusion [12]. The operative time was $171 \mathrm{~min}$, and the volume of blood loss during the surgery was little for uncountable. The cumulative time of Pringle method was $58 \mathrm{~min}$. The postoperative course was uneventful. Macroscopic examination revealed a dark brown tumor (Fig. 2a); microscopically, the tumor consisted of atypical cell proliferation with a papillary structure (Fig. 2b). Immunohistochemically, the resected specimen revealed that the tumors were positive for thyroid transcription factor- 1 and paired box 8 and slightly positive for thyroglobulin (Fig. 2c). The final diagnosis was metastatic liver tumor from TPC. The surgical margins were free of tumor.

The patient was discharged 7 days after the operation without complications. Two months after surgery, the patient underwent complementary thyroidectomy (right thyroidectomy) and right supraclavicular lymph node dissection, followed by I-131 ablation. The final diagnosis was papillary thyroid carcinoma of $7 \mathrm{~mm}$ and $4 \mathrm{~mm}$ and lymph node metastasis of $9 \mathrm{~mm}$. The patient has had no recurrence 1 year after surgery.

\section{Discussion}

PTC is the most common type of thyroid carcinoma, with an occurrence of about 75 to $80 \%$ [13]. Although (a)

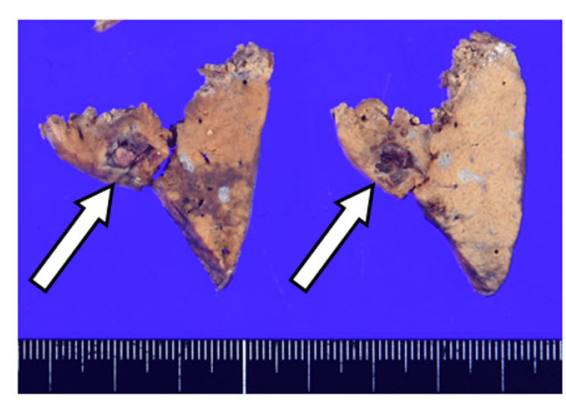

(b)

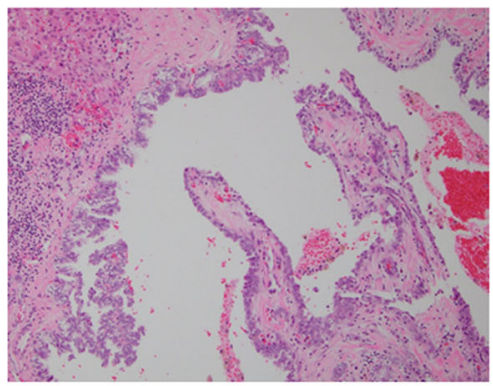

(c)

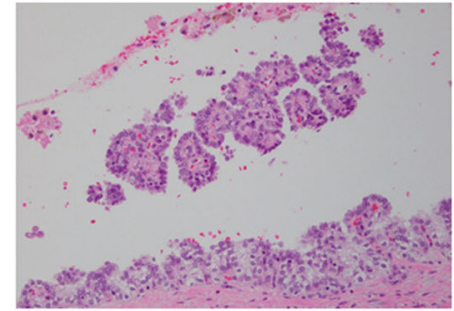

Hematoxylin and eosin staining

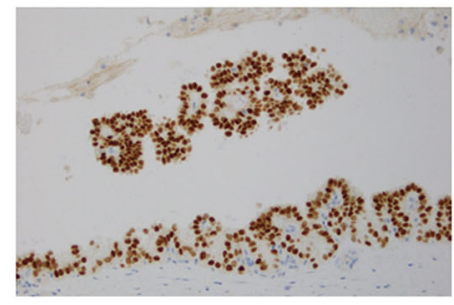

PAX8

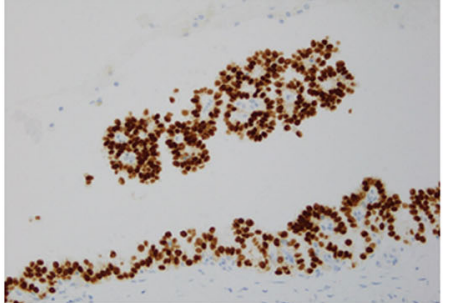

TTF-1

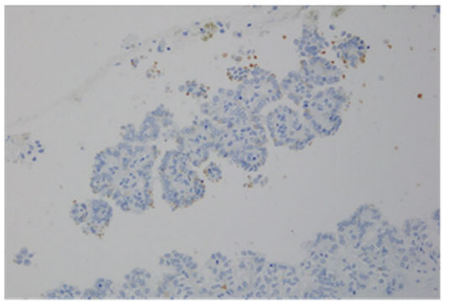

Thyroglobulin

Fig. 2 a Pathological finding showing a dark brown tumor (arrow). b Microscopically, the tumor consists of atypical cell proliferation with a papillary structure. $\mathbf{c}$ Immunohistochemically, the resected specimen revealed that the tumors are positive for thyroid transcription factor- 1 and paired box 8 and slightly positive for thyroglobulin 
PTC is usually associated with favorable prognosis, the presence of distant metastases is the most significant prognostic factor and correlates with poor prognosis but is often overlooked in clinical practice $[1,5,7,8]$. In the present case, liver metastasis was found early by $\mathrm{CT}$ with regular follow-up, and surgical resection could be performed.

The frequency of distant metastases in PTC is reported to be approximately $5-6 \%[4,5]$. Among patients with distant metastases, $45.5 \%$ occurred synchronously with the primary tumor [4]. Czepczynski et al. showed that among 1200 thyroid carcinoma patients, fewer than $1 \%$ had distant metastases detected at the time of the initial diagnosis [14]. Thus, it is relatively common for distant metastases to appear many years after the initial primary thyroid cancer surgery. Previous reports have described finding late distant metastases, other than liver metastases, more than 30 years after the initial resection of primary thyroid cancer $[15,16]$. Prior to our case, only 4 cases have been reported in which liver metastases were found more than 10 years after thyroidectomy. Brient et al. reported that the mean time of onset of first liver metastases of DTC was 52 months, while the longest delay was 13 years [17]. Kouso et al. [18] reported a case of a solitary liver metastasis 32 years after curative resection of follicular thyroid carcinoma; they performed laparoscopic liver resection, but the preoperative diagnosis was primary hepatocellular carcinoma.

In the present case, the patient had lung metastasis 41 years after initial thyroid surgery and liver metastasis 43 years after initial surgery. While PTC often metastasizes to the neck lymph nodes, lungs, and bones, liver metastases are very rare and may occur with a later onset [15, 17-20]. The appearance of liver metastasis is considered to represent the terminal phase of the disease, and the prognosis is poor [7, 19, 21]. Liver metastases of DTC do not normally accumulate radioiodine because of a dedifferentiation process [19]. Therefore, scintigraphy alone during follow-up is not sufficient to detect liver metastases, and CT and/or FDG PET should also be employed [7]. In the present case, liver metastasis could be detected early by CT scan. Early detection of such distant metastases has a significant impact on treatment decisions and prognosis of the patient.

Surgery, radiotherapy, and radioactive iodine (RAI, also called I-131) ablation therapy have been used for the treatment of liver metastases from PTC. Liver resection has been reported to prolong the survival in these patients if liver metastasis is solitary [18, 22-24]. Djenic et al. advocate liver resection of solitary metastasis of DTC only if free resection margin is possible [25]. For the present case, liver metastasis of PTC could be completely resected by laparoscopic partial liver resection for segment 2 . The patient had no recurrence after complementary thyroidectomy and right supraclavicular lymph node dissection followed by I-131 ablation.

Thyroid and liver diseases would interact or influence each other. The liver has an important role in thyroid hormone transport and metabolism. There is also evidence that the level of thyroid hormones may directly affect the liver structure or function [26, 27]. Regarding malignancies, some cases have been reported about the association between the thyroid and liver. Toshima et al. [28] reported a rare case of solitary thyroid metastasis from hepatocellular carcinoma detected by FDG-PET/CT.

In this case, the resected liver mass was confirmed as metastatic PTC via pathological examination and immunohistochemical analyses. Pathological examination showed two small masses in the right lobe of the thyroid. It cannot be ruled out that the primary PTC may have been present in the right lobe of the thyroid before hepatectomy; however, the patient did not present with positive signs in the thyroid by various radiological images. In cases where liver metastasis of PTC is suspected, liver resection should be considered as it offers the possibility of prolonged survival.

\section{Conclusions}

In conclusion, liver metastases from PTC may be found after long-term follow-up of 40 years or more. Liver resection might be the most appropriate treatment of liver metastases from PTC.

\section{Abbreviations \\ CT: Computed tomography; DTC: Differentiated thyroid carcinoma; FDG- PET: Fluorodeoxyglucose positron emission tomography; PTC: Papillary thyroid carcinoma}

\section{Acknowledgements \\ None.}

\section{Authors' contributions}

All authors declare that they contributed to this article and that they read and approved the final manuscript. MT reported the case and wrote the manuscript. MT, NH, KA, NK, AW, TI, NI, and KS performed the surgery and perioperative management of the patient and helped draft the manuscript. TY, TS, and KS participated in revising the manuscript critically.

\section{Funding}

The authors declare that they have no financial support in association with this case report.

\section{Availability of data and materials}

The datasets supporting the conclusions of this article are included within the article.

Ethics approval and consent to participate Not applicable.

\section{Consent for publication}

Written informed consent was obtained from the patient for publication of this case report and any accompanying images.

Competing interests

The authors declare that they have no competing interests. 


\section{Author details}

'Department of Innovative Cancer Immunotherapy, Gunma University Graduate School of Medicine, 3-39-22 Showa-machi, Maebashi, Gunma 371-8511, Japan. '2Division of Hepatobiliary and Pancreatic Surgery, Integrative Center of General Surgery, Gunma University Hospital, 3-39-15 Showa-machi, Maebashi, Gunma 371-8511, Japan. ${ }^{3}$ Department of Diagnostic Pathology, Gunma University Graduate School of Medicine, 3-39-22 Showa-machi, Maebashi, Gunma 371-8511, Japan.

Received: 13 May 2020 Accepted: 10 June 2020

Published online: 18 June 2020

\section{References}

1. Tubiana M, Schlumberger M, Rougier P, Laplanche A, Benhamou E, Gardet $P$, et al. Long-term results and prognostic factors in patients with differentiated thyroid carcinoma. Cancer. 1985;55:794-804.

2. Schlumberger MJ. Papillary and follicular thyroid carcinoma. N Engl J Med. 1998:338:297-306.

3. Ito $Y$, Miyauchi A, Kihara M, Fukushima M, Higashiyama T, Miya A. Overall survival of papillary thyroid carcinoma patients: a single institution longterm follow-up of 5897 patients. World J Surg. 2018;42:615-22.

4. Benbassat CA, Mechlis-Frish S, Hirsch D. Clinicopathological characteristics and long-term outcome in patients with distant metastases from differentiated thyroid cancer. World J Surg. 2006:30:1088-95.

5. Mizukami Y, Michigishi T, Nonomura A, Hashimoto T, Terahata S, Noguchi $M$, et al. Distant metastases in differentiated thyroid carcinomas: a clinical and pathologic study. Hum Pathol. 1990;21:283-90.

6. Madani A, Jozaghi Y, Tabah R, How J, Mitmaker E. Rare metastases of welldifferentiated thyroid cancers: a systematic review. Ann Surg Oncol. 2015;22: 460-6.

7. Song HJ, Xue YL, Xu YH, Qiu ZL, Luo QY. Rare metastases of differentiated thyroid carcinoma: pictorial review. Endocr Relat Cancer. 2011;18:R165-74.

8. Song HJ, Xue YL, Qiu ZL, Luo QY. Uncommon metastases from differentiated thyroid carcinoma. Hell J Nucl Med. 2012;15:233-40.

9. Araki K, Harimoto H, Ishii N, Tsukagoshi M, Igarashi T, Watanabe A, et al. Optimal indications for an intercostal port for the superior segments in laparoscopic partial liver resection. Asian J Endosc Surg. 2019. https://doi. org/10.1111/ases.12753.

10. Jones RM, Moulton CE, Hardy KJ. Central venous pressure and its effect on blood loss during liver resection. Br J Surg. 1998;85:1058-60.

11. Iguchi T, Ikegami T, Fujiyoshi T, Yoshizumi T, Shirabe K, Maehara Y. Low positive airway pressure without positive end-expiratory pressure decreases blood loss during hepatectomy in living liver donors. Dig Surg. 2017;34: 192-6.

12. Kobayashi S, Honda G, Kurata M, Tadano S, Sakamoto K, Okuda Y, et al. An experimental study on the relationship among airway pressure, pneumoperitoneum pressure, and central venous pressure in pure laparoscopic hepatectomy. Ann surg. 2016;263:1159-63.

13. Cobin $\mathrm{RH}$, Gharib H, Bergman DA, Clark OH, Cooper DS, Daniels GH, et al. AACE/AAES medical/surgical guidelines for clinical practice: management of thyroid carcinoma. American Association of Clinical Endocrinologists. American College of Endocrinology. Endocr Pract. 2001;7:202-20.

14. Czepczynski R, Wyszomirska A, Gryczynska M, Szczepanek-Parulska E, Ruchala M. Cerebellar metastasis of papillary thyroid carcinoma detected with somatostatin receptor scintigraphy. Endokrynol Pol. 2018;69:24-7.

15. Fonseca $P$. Thyroid lung metastasis diagnosed 47 years after thyroidectomy. Ann Thorac Surg. 1999;67:856-7.

16. Johnson MW, Morettin LB, Sarles HE, Zaharopoulos P. Follicular carcinoma of the thyroid metastatic to the kidney 37 years after resection of the primary tumor. J Urol. 1982;127:114-6.

17. Brient C, Mucci S, Taieb D, Mathonnet M, Menegaux F, Mirallie E, et al. Differentiated thyroid cancer with liver metastases: lessons learned from managing a series of 14 patients. Int Surg. 2015;100:490-6.

18. Kouso H, Ikegami T, Ezaki T, Ishida T, Aimitsu S, Fujihara M. Liver metastasis from thyroid carcinoma 32 years after resection of the primary tumor: report of a case. Surg Today. 2005;35:480-2.

19. Kraft O. Hepatic metastasis of differentiated thyroid carcinoma. Nucl Med Rev Cent East Eur. 2005;8:44-6.

20. Cady B, Meissner WA, Sala LE. Thyroid cancer for forty-one years. N Engl J Med. 1978;299:901.
21. Elisei R, Molinaro E, Agate L, Bottici V, Masserini L, Ceccarelli C, et al. Are the clinical and pathological features of differentiated thyroid carcinoma really changed over the last 35 years? Study on 4187 patients from a single Italian institution to answer this question. J Clin Endocrinol Metab. 2010;95:1516-27.

22. Adam R, Chiche L, Aloia T, Elias D, Salmon R, Rivoire M, et al. Hepatic resection for noncolorectal nonendocrine liver metastases: analysis of 1,452 patients and development of a prognostic model. Ann Surg. 2006;244:524-35.

23. Ohwada S, lino $Y$, Hosomura $Y$, Kon $Y$, Kawashima $Y$, Kasahara M, et al. Solitary metastasis from papillary thyroid carcinoma in cirrhotic liver with hepatocellular carcinoma. Jpn J Clin Oncol. 1993;23:309-12.

24. Ligocka J, Patkowski W, Szparecki G, Ostrowski T, Wiechno W, Zieniewicz K. Resection of liver metastases from differentiated thyroid cancer: who might benefit? A report of 2 cases with review of literature. Pol Przegl Chir. 2018; 91:52-6.

25. Djenic B, Duick D, Newell JO, Demeure MJ. Solitary liver metastasis from follicular variant papillary thyroid carcinoma: a case report and literature review. Int J Surg Case Rep. 2015;6C:146-9.

26. Huang MJ, Liaw YF. Clinical associations between thyroid and liver diseases. J Gastroenterol Hepatol. 1995;10:344-50.

27. Malik R, Hodgson $\mathrm{H}$. The relationship between the thyroid gland and the liver. QJ Med. 2002;95:559-69.

28. Toshima T, Taketomi A, Shirabe K, Takeishi K, Motomura T, Mano Y, et al. Solitary asymptomatic thyroid metastasis from hepatocellular carcinoma detected by FDG-PET/CT. Case Rep Gastroenterol. 2010:4:279-85.

\section{Publisher's Note}

Springer Nature remains neutral with regard to jurisdictional claims in published maps and institutional affiliations.

\section{Submit your manuscript to a SpringerOpen ${ }^{\circ}$ journal and benefit from:}

- Convenient online submission

- Rigorous peer review

- Open access: articles freely available online

High visibility within the field

- Retaining the copyright to your article

Submit your next manuscript at $>$ springeropen.com 